\title{
ANALISIS BIOETANOL DARI LIMBAH KULIT BUAH SUKUN (Artocarpus altilis) DENGAN CARA HIDROLISIS DAN FERMENTASI
}

\author{
Analysis of Bioethanol from Peel Waste of the Breadfruit (Artocarpus altilis) through Hydrolysis \\ and Fermentation
}

\author{
*Fardiana, Purnama Ningsih dan Kasmudin Mustapa \\ Pendidikan Kimia/FKIP - Universitas Tadulako, Palu - Indonesia 94118 \\ Received 8 December 2017, Revised 9 January 2018, Accepted 8 February 2018
}

\begin{abstract}
This study aimed to determine glucose and ethanol levels from fermentation of peel waste of breadfruit. Glucose level was determined using UV-Vis spectrophotometer and then continued with fermentation of glucose from hydrolysis process using yeast tape (saccharomyces cerevisiae) for 3 days to produce bioethanol. The step in this study was the sample preparation, the acid variations in hydrolysis with $\mathrm{HCl}, \mathrm{H}_{2} \mathrm{SO}_{4}, \mathrm{H}_{3} \mathrm{PO}_{4}(10 \%)$ and the fermentation. Determination of ethanol from the fermentation of glucose was measured by using alkoholmeter. The highest glucose level was $0.68 \%$ which was from hydrolysis using $\mathrm{HCl}$ and the highest ethanol level was $9 \%$ which obtained from the fermentation of glucose by using HCl hydrolysis. The conclusion shows that the type of acid used to reach optimum hydrolysis of the breadfruit's peel is $\mathrm{HCl}$.
\end{abstract}

Keywords: Acid hydrolysis, bioethanol, caucasian breadfruit, fermentation.

\section{Pendahuluan}

Bioetanol dapat diproduksi menggunakan bahan baku tanaman yang mengandung pati, karbohidrat dan selulosa melalui proses biokonversi karbohidrat menjadi gula (glukosa) yang larut dalam air (Irvan, dkk., 2015). Salah satu contohnya adalah etanol dapat diproduksi dengan cara fermentasi menggunakan bahan baku hayati yang dihasilkan dari fermentasi gula yang mengandung bahan seperti tetes tebu (sari tebu atau sirup tebu), berbagai jenis tanaman, gula bit dan jagung manis (Umamaheswari, dkk., 2010). Proses pembuatan bioetanol meliputi proses hidrolisis, dan fermentasi. Setiap tahapan proses ini sangat berpengaruh terhadap hasil akhir dari produk bioetanol yang dihasilkan.

Proses hidrolisis bertujuan untuk merusak struktur dari selulosa, sehingga dapat meningkatkan porositas bahan. Rusaknya struktur selulosa akan mempermudah terurainya selulosa menjadi glukosa (Sukowati, dkk., 2014). Asam yang biasa digunakan untuk menghidrolisis selulosa adalah $\mathrm{HCl}, \mathrm{H}_{2} \mathrm{SO}_{4}$ dan $\mathrm{H}_{3} \mathrm{PO}_{4}$. Jenis asam yang digunakan pada proses hidrolisis ini memegang peranan penting terhadap kadar glukosa yang dihasilkan. Kadar glukosa berpengaruh terhadap kadar bioetanol setelah melewati proses fermentasi.

Metode lanjutan yang sering digunakan pada pembuatan bioetanol yaitu menggunakan fermentasi. Proses fermentasi dasar melibatkan kegiatan enzimatik lactobacilli, leuconostoc,

\footnotetext{
*Correspondence

Fardiana

Program Studi Pendidikan Kimia, Fakultas Keguruan dan Ilmu Pendidikan, Universitas Tadulako

e-mail: Fdiana838@gmail.com

Published by Universitas Tadulako2018
}

pediococci, ragi dan jamur. Metabolisme mereka menghasilkan produksi rantai pendek asam lemak seperti laktat, asetat, butirat format dan asam propionate (Kohajdova \& Karovicova, 2007).

Proses fermentasi melibatkan reaksi kimia oleh fungi atau bakteri, salah satu yang sering digunakan adalah bakteri Saccharomyces cerevisiae. Saccharomyces cerevisiae mempunyai kelebihan yaitu lebih cepat pertumbuhan selnya dan mudah menguraikan glukosa, fruktosa, dan sukrosa untuk memproduksi etanol tetapi juga memiliki beberapa kekurangan di antaranya adalah tidak tahan dengan suhu tinggi (Jhonprimen, dkk., 2012).

Indonesia memiliki berbagai jenis buah-buahan dalam jumlah yang banyak. Salah satunya adalah buah sukun (Artocarpus altilis). Sukun (Artocarpus altilis) merupakan salah satu jenis tanaman yang sudah lama dibudidayakan oleh masyarakat Indonesia bahkan di beberapa negara di kawasan Pasifik. Sukun mengandung karbohidrat dan gizi yang baik seperti kalsium, posforus, dan vitamin C. Hasil buah sukun antara 200-700 buah per pohon per tahun (Puspitojati, dkk., 2014). Tanaman sukun dapat menghasilkan limbah pertahun \pm 350 $\mathrm{kg}$ per pohon diantaranya kulit dan isi (Pratiwi, 2011). Kulit buah sukun yang termasuk biomassa mengandung selulosa sehingga sangat dimungkinkan untuk dimanfaatkan menjadi bioetanol (Pratiwi, 2011).

Biomassa selulosa mula-mula dilakukan hidrolisis baik secara kimia atau enzimatik untuk merusak unit polimer dan meningkatkan aksesibilitas gula $\mathrm{C}_{5}-\mathrm{C}_{6}$ pada proses fermentasi menggunakan mikroba untuk menghasilkan etanol (Devarapalli \& Atiyeh, 2015). Melalui proses hidrolisis, selulosa potensial diubah menjadi glukosa yang mempunyai nilai ekonomi tinggi. Perubahan selulosa menjadi glukosa merupakan tahap yang strategis karena glukosa dibutuhkan 
untuk berbagai keperluan. Glukosa dapat difermentasi lebih lanjut menjadi asam organik dan etanol. Salah satu produk nilai tambah dari limbah selulosa adalah bioetanol (Anindyawati, 2010).

Karya ilmiah ini dimaksudkan untuk mendeskripsikan jenis katalis asam yang optimum dalam menghidrolisis selulosa menjadi glukosa dan kadar bioetanol tertinggi dari fermentasi glukosa hasil hidrolisis pada sampel kulit buah sukun.

\section{Metode}

\section{Alat dan Bahan}

Alat yang digunakan dalam penelitian adalah neraca analitik (AND GR-200), peralatan gelas, $\mathrm{pH}$ meter ( $\mathrm{La}$ Motte), alkoholmeter, spektrofotometer UV-Vis (GANESYS 10 UV) dan seperangkat alat evaporator (EYELA SB-1100).

Bahan yang digunakan adalah limbah kulit dari buah sukun yang tumbuh di wilayah Sigi Biromaru, larutan $\mathrm{HCl} \quad 10 \%$ (MALLINCKROOT), larutan $\mathrm{H}_{2} \mathrm{SO}_{4} 10 \%$ (JHD TM), larutan $\mathrm{H}_{3} \mathrm{PO}_{4} 10 \%$ (Merck), $\mathrm{NaOH} 6 \mathrm{M}$ (Merck), Glukosa (Merck KGaA), Antrone (Merck), urea (Merck KGaA), ammonium sulfat (Merck), ragi tape (Saccharomyces cerevisiae), dan aquades.

\section{Perlakuan sampel kulit sukun}

Kulit buah sukun dipotong-potong sampai ukuran $\pm 3 \mathrm{~cm}$ kemudian dikeringkan di bawah sinar matahari selama 3 hari. Kulit buah sukun yang sudah kering selanjutnya dihaluskan menggunakan penggilingan (grinder) kemudian diayak sampai diperoleh sampel dalam bentuk serbuk kira-kira sampai ukuran partikel 40 mesh. Selanjutnya serbuk dipanaskan menggunakan oven pada suhu $60{ }^{\circ} \mathrm{C}$ selama 2 jam (Fachry, dkk., 2013).

\section{Proses Hidrolisis}

Serbuk kulit buah sukun sebanyak 60 gram dibagi menjadi tiga bagian dan dimasukkan ke dalam gelas kimia. Bagian pertama ditambahkan $\mathrm{HCl} 10 \%$, bagian kedua ditambahkan $\mathrm{H}_{2} \mathrm{SO}_{4} 10 \%$ dan bagian ke tiga ditambahkan $\mathrm{H}_{3} \mathrm{PO}_{4} \quad 10 \%$ masing-masing sebanyak $200 \mathrm{~mL}$ (Fachry, dkk., 2013). Campuran dipanaskan pada suhu $120{ }^{\circ} \mathrm{C}$ selama 1 jam, kemudian disaring, dan filtratnya dianalisis kandungan glukosanya menggunakan spektrofotometer UV-Vis pada panjang gelombang 630 nm (Putri \& Sukandar, 2008).

\section{Proses fermentasi}

Masing-masing filtrat hasil hidrolisis diatur $\mathrm{pH}$ larutannya hingga $\mathrm{pH} 5$ dengan menambahkan larutan larutan $\mathrm{NaOH} 6 \mathrm{M}$ lalu diambil sebanyak $70 \mathrm{~mL}$ untuk dimasukkan ke dalam Erlenmeyer, masing-masing larutan tersebut ditambahkan 0,08 gram urea dan 0,15 gram ammonium sulfat. Selanjutnya di-pasteurisasi pada suhu $80{ }^{\circ} \mathrm{C}$ selama 15 menit, lalu ditambahkan 2 gram ragi tape (Saccharomyces cerevisiae). Semua erlenmeyer ditutup dengan aluminium foil dan dilakukan pendiaman dengan waktu 3 hari pada suhu 27-30 ${ }^{\circ} \mathrm{C}$ (Sari, dkk., 2008).

\section{Proses Evaporasi}

Cairan hasil fermentasi dievaporasi untuk memisahkan etanol dengan campurannya secara fisik sehingga diperoleh kadar etanol yang lebih tinggi, yaitu cairan hasil fermentasi dimasukan ke dalam labu evaporator kemudian labu dipasang pada rangkaian alat evaporator. Pada proses ini dilakukan pemanasan pada suhu $78-80{ }^{\circ} \mathrm{C}$ karena titik didih etanol $78,3^{\circ} \mathrm{C}$. Larutan hasil evaporasi selanjutnya ditentukan kadarnya dengan menggunakan alkoholmeter (Moeksin \& Francisca, 2010).

\section{Hasil dan Pembahasan}

\section{Analisis Kadar Glukosa dari Hasil Hidrolisis}

Dalam penelitian ini sampel kulit buah sukun yang telah dihidrolisis menggunakan tiga jenis asam yaitu $\mathrm{HCl}(10 \%), \mathrm{H}_{2} \mathrm{SO}_{4}(10 \%)$ dan $\mathrm{H}_{3} \mathrm{PO}_{4}$ (10\%) diperoleh kadar glukosa tertinggi dengan menggunakan $\mathrm{HCl} 10 \%$ yakni sebesar $0,68 \%$ (dapat dilihat pada Tabel 1). Sesuai dengan teori keelektronegatifan atom pusat, semakin elektronegatif senyawanya maka daya tariknya semakin besar dan bersifat semakin asam. Menurut Arrhenius, asam adalah zat yang dalam air melepaskan ion $\mathrm{H}^{+}$, kecenderungan dalam sistem periodik adalah dalam satu periode sifat keasaman semakin meningkat dari kiri ke kanan, hal ini dikarenakan unsur tersebut semakin mudah melepas $\mathrm{H}^{+}$dalam ikatannya (Chang, 2004). Cl, S dan $\mathrm{P}$ merupakan satu periode sehingga urutan kekuatan asam adalah $\mathrm{HCl}>\mathrm{H}_{2} \mathrm{SO}_{4}>\mathrm{H}_{3} \mathrm{PO}_{4}$. Sehingga semakin kuat suatu asam maka kadar glukosa yang dihasilkan semakin besar. Asam dalam hal ini bertindak sebagai katalisator yang bertujuan untuk mempercepat jalannya reaksi hidrolisis.

Tabel 1 Kadar glukosa hasil hidrolisis

\begin{tabular}{clc}
\hline No. & \multicolumn{1}{c}{ Hidrolisis } & Glukosa (\%) \\
\hline 1 & $\mathrm{HCl} 10 \%$ & 0,68 \\
2 & $\mathrm{H}_{2} \mathrm{SO}_{4} 10 \%$ & 0,39 \\
3 & $\mathrm{H}_{3} \mathrm{PO}_{4} 10 \%$ & 0,24 \\
\hline
\end{tabular}

Berdasarkan pengujian yang dilakukan, kadar gula pereduksi yang dihasilkan dari hidrolisis dengan $\mathrm{HCl}, \mathrm{H}_{2} \mathrm{SO}_{4}$ dan $\mathrm{H}_{3} \mathrm{PO}_{4}$ tidak berpengaruh secara signifikan. Hal ini terjadi karena asam memecah molekul pati secara acak sehingga hasil hidrolisis sampel kulit buah sukun sulit untuk diprediksikan (Putri \& Sukandar, 2008). Tinggi rendahnya kadar glukosa juga dipengaruhi oleh banyak sedikitnya selulosa yang dapat dikonversi menjadi glukosa selama proses hidrolisis berlangsung. Sehingga semakin banyak jumlah selulosa yang dikonversi selama proses hidrolisis maka semakin tinggi pula kadar glukosa.

Glukosa hasil hidrolisis difermentasi menggunakan ragi tape (saccaromyces cereviceae). Penggunaan ragi tape lebih optimal karena lebih 
banyak mikrorganisme yang dapat menguraikan glukosa menjadi gula yang lebih sederhana dan pada waktu fermentasi mikroba pada ragi tape lebih cepat beradaptasi (Johnprimen, 2012). Tahapan fermentasi pula ditambahkan bahan pendukung berupa nutrisi. Hal ini dikarenakan pada proses fermentasi, mikoroorganisme sangat memerlukan nutrisi yang baik agar dapat diperoleh hasil fermentasi yang baik pula. Oleh karena itu, nutrisi yang tepat untuk menyuplai mikroorganisme adalah nitrogen yang mana dapat diperolah dari penambahan urea serta nutrisi yang lain yaitu amonium sulfat (Sari, dkk., 2008).

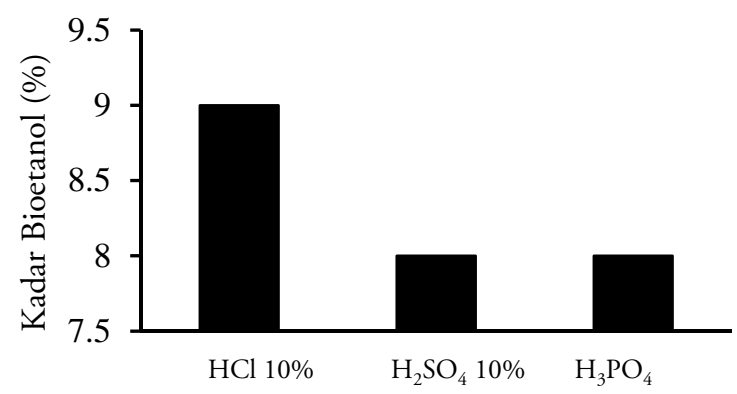

Gambar 1 Kadar bioetanol kulit buah sukun

Grafik yang di tunjukkan pada Gambar 1 dapat diketahui bahwa kadar bioetanol yang diperoleh sesuai dengan kadar glukosa yang diperoleh dari proses hidrolisis. Dimana, semakin tinggi kadar glukosa hasil hidrolisis maka semakin tinggi pula kadar bioetanol yang dihasilkan hal ini dikarenakan banyaknya jumlah glukosa yang dapat dikonversi oleh mikroba Saccharomyces cereviceae menjadi etanol pada proses fermentasi (Widjaja, dkk., 2009).

Penelitian ini diyakini bahwa jenis alkohol yang diperoleh adalah etanol (etil alkohol), hal ini dikarenakan pada tahapan fermentasi menggunakan mikroba Saccaromyces cereviceae. Produksi etanol dari glukosa oleh Saccaromyces cerevisiae terjadi melalui jalur Embden-MeyerhofParnas (EMP) yang terbagi dalam 3 tahap. Tahap pertama merupakan tahap perubahan glukosa (C6) menjadi 2 molekul gliseraldehid-3-fosfat (C3) menggunakan ATP. Reaksi oksidasi-reduksi dan pelepasan energi tidak terjadi pada tahap pertama. Kedua reaksi tersebut baru terjadi dalam tahap kedua dan menghasilkan energi berupa ATP. Piruvat sebanyak 2 mol juga dihasilkan dalam tahap ini. Tahap ketiga merupakan tahap terjadinya reaksi oksidasi-reduksi yang kedua dan pembentukkan produk fermentasi, asam piruvat dikatalisis oleh enzim alkohol dehidrogenase oleh enzim piruvat 20 dekarboksilase menjadi asetaldehida dan diubah menjadi etanol (Irawan, 2012)

Alkohol yang dihasilkan dalam proses evaporasi belum tentu $100 \%$ etanol, untuk mengetahui hal itu maka dilakukan pengukuran kadar alkohol dengan alkoholmeter. Alkoholmeter berfungsi untuk membaca presentase alkohol yang diperoleh. Prinsip kerja dari alkoholmeter berdasarkan berat jenis campuran antara alkohol dengan air. Cara pengukurannya yaitu memasukkan alkoholmeter ke dalam gelas ukur yang panjangnya melebihi alkoholmeter dan dalam gelas ukur tersebut telah berisi cairan etanol yang akan diukur. Alkoholmeter akan tenggelam dan batas cairannya akan menunjukan berapa kandungan etanol dalam larutan tersebut (Mailool, dkk., 2013).

\section{Hubungan kadar glukosa terhadap kadar bioetanol}

Hubungan antara kadar glukosa terhadap kadar bioetanol yang dihasilkan pada penelitian ini dapat dilihat pada Gambar 2.

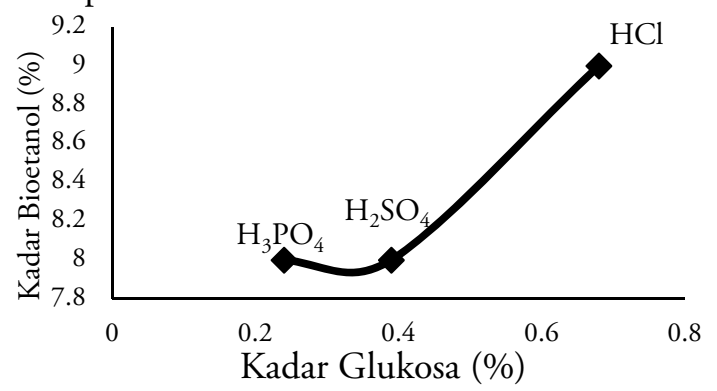

Gambar 2 Hubungan antara kadar glukosa dan kadar bioetanol

Penggunaan asam yang berbeda pada proses hidrolisis mempengaruhi kadar glukosa seperti yang terlihat pada grafik yang ditunjukkan pada Gambar 2 meskipun demikian kadar bioetanol tidak memberikan perbedaan hasil yang begitu signifikan. Menurut Judoamidjojo (1990), tinggi rendahnya kadar alkohol selain dapat ditentukan dari substrat gula yang terfermentasi juga ditentukan pula oleh aktifitas khamir pada saat proses fermentasi berlangsung. Kadar bioetanol yang diperoleh tidak memberikan perbedaan hasil yang begitu signifikan dikarenakan waktu fermentasi belum mencapai keadaan optimum dari masing-masing substrat yang terfementasi, yaitu belum semua glukosa diubah menjadi etanol oleh sel-sel khamir (Saccaromyces cereviceae).

\section{Kesimpulan}

Berdasarkan hasil penelitian dan pembahasan maka dapat disimpulkan bahwa, penggunaan asam yang berbeda pada proses hidrolisis mempengaruhi kadar glukosa dari limbah kulit buah sukun yaitu pada proses hidrolisis menggunakan $\mathrm{HCl}$ sebesar 0,68\%, menggunakan $\mathrm{H}_{2} \mathrm{SO}_{4}$ sebesar $0,39 \%$, dan menggunakan $\mathrm{H}_{3} \mathrm{PO}_{4}$ sebesar $0,24 \%$. Walaupun demikian kadar bioetanol tidak memberikan perbedaan hasil yang signifikan, kadar bioetanol dari glukosa yang diperoleh dari hasil hidrolisis menggunakan $\mathrm{HCl}$ sebesar 9\%, menggunakan $\mathrm{H}_{2} \mathrm{SO}_{4}$ sebesar $8 \%$, dan menggunakan $\mathrm{H}_{3} \mathrm{PO}_{4}$ sebesar $8 \%$.

\section{Ucapan Terima Kasih}

Ucapan terimakasih penulis sampaikan kepada Husnia, Nurbaya dan Tasrik, yang telah memberikan bimbingan dan masukan dalam menyelesaikan penelitian ini 


\section{Referensi}

Anindyawati, T. (2010). Potensi selulase dalam mendegradasi lignoselulosa limbah pertanian untuk pupuk organik. Jurnal Berita Selulosa, 45(2), 70-77.

Chang, R. (2004). Kimia dasar: Konsep-konsep inti. Jakarta: Erlangga.

Devarapalli, M. \& Atiyeh, H. K. (2015). A review of conversion processes for bioethanol production with a focus on syngas fermentation. Biofuel Research Journal, 2(3), 268-280.

Fachry, A. R., Astuti, P. \& Puspitasari, T. G. (2013). Pembuatan bioetanol dari limbah tongkol jagung dengan variasi konsentrasi asam klorida dan waktu fermentasi. Jurnal Teknik Kimia, 19(1), 60-69.

Irawan, E. P. (2012). Optimasi produksi bioetanol dari tepung garut (Maranta arundinacea linn.) dengan variasi $\mathrm{pH}$, kdar pati dan sumber khamir komersial. Retrieved from http://ejournal.uajy.ac.id/34/3/2BL01046.pdf website:

Irvan, Prawati, P. \& Trisakti, B. (2015). Pembuatan bioetanol dari tepung ampas tebu melalui proses hidrolisis termal dan fermentasi: pengaruh $\mathrm{pH}$, jenis ragi dan waktu fermentasi. Jurnal Teknik Kimia USU, 4(2), 27-31.

Johnprimen, H. S., Turnip, A. \& Dahlan, M. H. (2012). Pengaruh massa ragi, jenis ragi dan waktu fermentasi bioetanol dari biji durian. Jurnal Teknik Kimia, 18(2), 43-51.

Judoamidjojo. (1990). Pengantar mikrobiologi. Jakarta: Departemen Pendidikan dan Kebudayaan, Dirjen Dikti.

Judoamidjojo, M., Darwis, A. A. \& Sa'id, E. G. (1992). Teknologi fermentasi. Jakarta: Rajawali Press.

Mailool, J. C., Molenaar, R., Tooy, D. \& Longdong, I. A. (2013). Produksi bioetanol dari singkong (Manihot utilissima) dengan skala laboratorium. COCOS, 2(1), 1-11.

Moeksin, R. \& Francisca, S. (2010). Pembuatan etanol dari bengkuang dengan variasi berat ragi, waktu dan jenis ragi. Jurnal Teknik Kimia, 17(2), 25-30.

Pratiwi, D. (2011b). Pemanfaatan sirup glukosa hasil hidrolisa selulosa dari kulit buah sukun (artocarpus altilis) dengan $\mathrm{HCl}$ 30\% untuk pembuatan manisan jambu biji (psidium guajava l.) dengan variasi konsentrasi. Medan: Universitas Sumatera Utara.

Puspitojati, T., Rachman, E. \& Ginoga, K. L. (2014). Hutan tanaman pangan realitas, konsep dan pengembangan. Retrieved from http://puspijak.org/upload_file/hutantanaman. pdf website:

Putri, L. S. E. \& Sukandar, D. (2008). Konversi pati ganyong (canna edulis ker.) menjadi bioetanol melalui hidrolisis asam dan fermentasi. Biodiversitas, 9(2), 112-116.

Sari, I. M., Noverita \& Yulneriwarni. (2008). Pemanfaatan jerami padi dan alang-alang dalam fermentasi etanol menggunakan kapang trichodermaviride dan khamir saccaromyces cereviceae. Vis Vitalis, 1(2), 55-62.

Sukowati, A., Sutikno \& Rizal, S. (2014). Produksi bioetanol dari kulit pisang melalui hidrolisis asam sulfat. Jurnal Teknologi dan Industri Hasil Pertanian, 19(3), 93-100.

Umamaheswari, M., Jayakumari, M., Maheswari, K., Subashree, M., Mala, P., \& Sevanthi, T., (2010). Bioethanol production from cellulosic materials. International Journal of Current Research, 1, 005-011.

Widjaja, T., Andina, M. \& Debby, A. K. W. (2009). Pengaruh konsentrasi gula terhadap produksi etanol dari molases dengan teknik immobilisasi sel. Prosiding Seminar Nasional Teknik Kimia Kejuangan. 